\title{
The philosophy of the workplace spirituality in the third millennium organizations: A field study at the ministry of health center
}

\author{
Noor Khalil Ibrahim ${ }^{1}$, Majeed Hameed Taher ${ }^{2}$ \\ ${ }^{1}$ College of Administration and Economics, University of Baghdad \\ ${ }^{2}$ College of Administration sciences and financial, University of Imam Jafar AL Sadeq
}

\begin{abstract}
Purpose: The research aims to build an integrated knowledge framework for the basic research topic. The spirituality of the workplace is through access to the most important scientific proposals on these topics. In management thought framing, the knowledge within them in a serious attempt is to provide the appropriate answers about the intellectual dilemma of research by diagnosing the nature of the relationship with the influential elements and its historical development .
\end{abstract}

Methodology: The study is relied on the analytical survey method. The research sample targeted (88) managers in the center of the Iraqi Ministry of Health exclusively from the researched senior leaders (general manager, assistant general manager, and head of department), and the main tool for research was represented by relying on solid international standards. The research variable has been adapted to the needs of the Iraqi environment. Hypotheses and data analysis have been tested using the appropriate statistical tools (arithmetic mean, standard deviation, differential coefficient and confirmatory factor analysis)

Theoretical results: The research results are formulated according to the process of intellectual reasoning and philosophical variables. Workplace spirituality in its broad sense encompasses a multidimensional concept linked to hope, desires, thinking patterns, emotions, feelings and behaviors. They are critical element in organizations' interactions with employees, customers and the community individuals were able to integrate into their careers and enhance their job satisfaction.

Practical Results: The results of the statistical analysis showed the weak interest of the Ministry of Health in the spirituality of the workplace, as a result of the Ministry's focus on routine official aspects and neglecting the spiritual aspects, feelings, and feelings of workers, which generally affected the organizational climate of the ministry. This leads to lost element of spiritual interaction that is mostly needed for ministry's work for spirituality in the workplace.

Originality / Value: Focusing on the emotional and spiritual aspect of the employees has presented in this study. Technological developments have adversely affected social communication between employees, and the sense of isolation has increased. This has adversely affected performance and creativity at work. So, it is necessary to increase the actual attention of spiritual reality in the workplace. This has evidenced by the fact that some organizations have begun to set up special sections dealing with the spirituality of the workplace as the case within the American Academy, the spirituality of management and the religious interests group (MSR Group) to address specific spiritual issues.

\begin{tabular}{ll}
\hline Keywords: & $\begin{array}{l}\text { Spirituality Workplace, 21st Century, Intellectual Schools of Management, Iraqi } \\
\text { Ministry of Health Center }\end{array}$ \\
\hline
\end{tabular}

\section{Corresponding Author:}

Noor Khalil Ibrahim

College of Administration and Economics, University of Baghdad

E-mail: noorkhalil@coadec.uobaghdad.edu.iq

\section{Introduction}

Experts and theorists in the field of administrative sciences have presented variety of theories, such as classical theories, humanism, organizational cooperation theory, decision-making theory of Herbert Simon, chaos theory and others to study and determine human behavior. The fact that the workplace spirituality in an organization is an emerging phenomenon that attracted the attention of many management and organizational experts. Accordingly, many experts consider spirituality to be a source of sustainable competitive advantage 
for the organization in the 21st century, which can help them in times of turmoil and resolve contradiction within the organization.

The study also showed that the scope of management and the theory of the organization is theoretically and practically influenced by formal and informal factors. The main issues have been emphasized in the theory of the organization in the 21st century with dating back to the nineties. The focus is on the subjects of religion, ethics and spirituality of the staff. They now recognize spirituality as an essential element of the workplace, and after 1990, the category of spirituality has also been considered in business and service environments, especially in areas where financial issues are heavily distributed. Some experts see spirituality as representing the three anchors basic regulatory decision which is the level of ambition, the expected rate of return and the level of satisfaction value, which would bring about a balance within the organization

\section{Research problem}

Most researchers and writers indicate that the present time is radically different time from the past, whether in terms of the environment, technology or intellectual skills required for organizations, and as organizations face various challenges and difficulties in a large environment of uncertainty and complexity as a result of a combination of technological and economic factors. This has affected the nature of the psychological situation experienced by the employees within the organizations, as we find that most of the employees feel at all times anxiety, pressure, isolation and fatigue career. This negatively affected the levels of spirituality of workers in the workplace due to many reasons. This includes increasing the hours, workload, and the weakness of the senior leadership skills in how to deal with the workers in addition to their focus on the official routine, neglecting the spirit of the individual worker and the possibility of employing him to serve himself and build positive attitudes towards their work in a way that benefits his organization. In addition, neglecting the behavioral role of the workers, increasing the complexity of public life experienced by the employee outside the work environment are existing. All these changes are negatively reflected on the employee and give him negative energy that does not give him spirituality in the workplace. The following is a summary of a set of questions that discussed in its content for the basic aspects of the entire research process:

- Is there an interest in the ministry for searching for the spirituality of the workplace?

- What are the levels of dimensions of workplace spirituality?

\section{Research importance}

- The research presents intellectual and philosophical controversies related to the nature of the workplace spirituality in public and private organizations during the third millennium and its implications for organizations and workers.

- The contribution of presenting theoretical and philosophical frameworks for the spirituality of the workplace and analysis in the light of the summary of ideas of researchers and thinkers of the of research subject.

- Enriching the administrative thought and opening new horizons for scientific research through achieving a state of integration among psychology, sociology and organizational behaviour.

- This research is considered as a scientific extension to contribute to bridge the knowledge gap that can be inferred from the intellectual propositions of researchers who contributed to the maturation of the intellectual dimension of the of the organization spirit.

\section{Workplace spirituality / evolution and development}

Workplace spirituality is considered as a highly subjective and philosophical view, and most academic interpretations acknowledge that it consists of a sense of being, and deep connections in the workplace and values. Stodd (2005) viewed spirituality as a transformative process that incorporates different aspects of physical, emotional, professional, intellectual and rational life [12]. 
Workplace spirituality has been conceived in a variety of contradictory forms such as "expressing an individual's perception of spiritual values within an organizational framework" [17], or a common understanding and disclosure of identical spiritual beliefs and behaviors among members of the organization [20]. At the organizational level, the most comprehensive and systematic empirical exploration of spirituality was conducted by Denton and Mitroff [19], who placed workplace spirituality in the organizational structure or strategic level, as a description of the organization's entity.

Some authors have pointed out that the understanding of WOS stems from organizational culture [6, 10], whereas Giacalone and Jurkiewicz defined WOS as a framework of organizational values reflected in a culture that enhances employees' experience of transcendence through the work process. As a component of organizational culture, this view of WOS facilitates their sense of communication with others in a way that provides feelings of completeness and joy. These stand for important details regarding the role that the employee and the organization play in the development of a spiritual workplace [17]. WOS can be understood through three perspectives: individual, organizational and interactive perspectives. WOS can be seen as how a person brings his / her set of ideas and spiritual values to the workplace. On the organizational level, WOS can be seen as a perception of the individual's spiritual values in the organization. The third perspective includes the perspective of the interaction of the relationship between the person's values and values provided by FAO. If we want to know the emergence and development about spirituality in the workplace, we will find that this concept has begun to evolve and develop with the emergence of the schools of thought management gradually, as the aspirant of the development of administrative thought and intellectual roots of his view that each stage has focused on one side without the other.

Taylor - Scientific Management (1900 - 1920s): Tyler interested in describing the characteristics of the human being as a relatively simple machine to perform a relatively simple duty. Tyler pointed out that the method of management used in American factories and based on the principle of the basis of financial returns or economic return did not achieve the necessary effectiveness. It did not raise productivity and should be changed to be based on scientific principles [1]. Thus, we see that the classical school focused on the body, where it analyzed the work mechanically and promised the individual working on the machine and making the orientation towards the material factors affecting his performance of the work more than other needs of safety and harmony and respect [1]. Therefore, we find that this basic stage was not seen as factor essential pillar in the process of organizational success and that there have been neglecting the feelings of humanity of the workers to come to the correct path at this point and is the humanitarian school.

The Human Relations Movement (1930-1940s) is considered as a reaction to scientific management. The most important studies carried out by the human relations movement are Hawthorne studies, which were supervised by Elton Mayo. These studies showed that there is a strong correlation between workers 'behavior and feelings, that the group affects individual behavior, and that the money is not as important to workers' output as the group's standards including feelings and security (Robbins, 2005). Moreover, researchers such as Mayo, 1933 note that workplace satisfaction depends on the informal nature of working groups. Some authors pointed out that this increase in interest in humanity was due to the shift in management practices within organizations, where they recognized the important role played by staff. Within the companies, they moved from a rigid and bureaucratic rigid management approach to a people-oriented approach $[3,4,19]$.

- Based on theory of Maslow in 1954, it was emphasized that the conditions for collective belonging and cooperation should be created and that humans have a hierarchy of five needs: physiological, social, safety, self-respect and fulfillment. According to Maslow, individuals need to meet low basic needs before reaching higher needs and noted that self-fulfilling people are those who have been fully achieved and have reached all they were able to do [6]. Maslow's workplace is the highness and self-realization to Maslow. 
- The theory of workers or two elements, the researchers proposed two sets of factors are preventive factors that are linked to the context or the environment in which the function is working and works to keep the individual away from the state of dissatisfaction, while the second group is stimulating factors such as achievement Responsibility, progress, and recognition of others are factors related to the content of the job. If available, individuals are satisfied with their job [24].

- McGregor in 1960 devised two theories $\mathrm{X}$ and $\mathrm{Y}$ to identify and analyze the behavior and characteristics of schools of classical management and human relations where both are based on a set of assumptions about the individual and the motives and behavior of leadership towards him where the theory presented $\mathrm{X}$ and $\mathrm{Y}$ theory as another way to understand, motivate and manage staff within organizations $\mathrm{Y}$ basically states that people usually accept and seek responsibility, and enjoy mental and physical work duties, and employees believe that work is normal, such as rest or play. Theory $\mathrm{X}$ believes that employees don't like work, and that they will try to avoid it whenever possible [1]. The two researchers argue that it is the $\mathrm{Y}$ who follow the theory of spirituality in the workplace, unlike the X-theory. More recently, there has been an increase in $\mathrm{Y}$ generation followers in international organizations who are said to be more perfect than some previous generations.

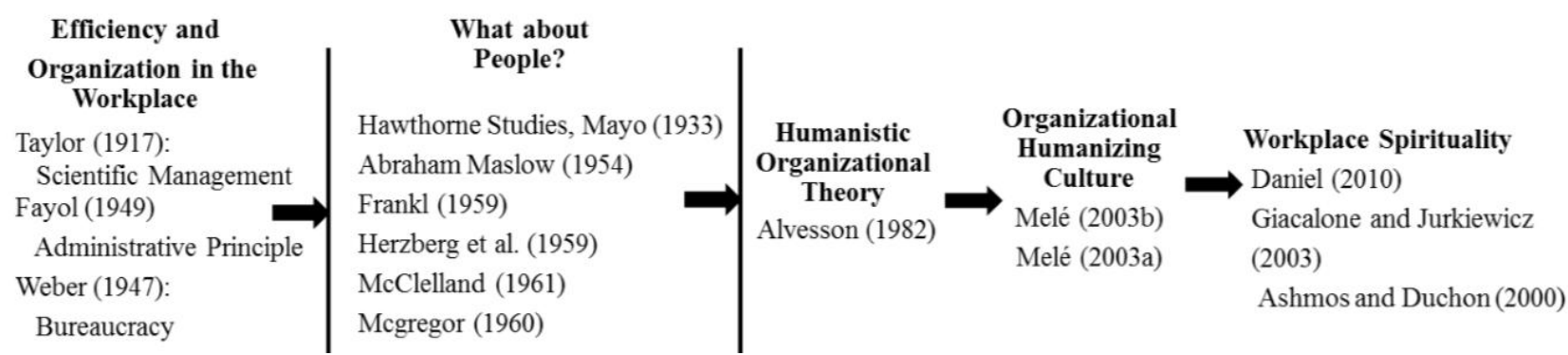

Figure 1. The humanistic approach [6]

\section{The importance of spirituality in the workplace}

The spirituality of the workplace has gained increasing attention over the past two decades among researchers, organizations, and the public and private sectors alike, due to the ever-changing nature of work, and the realization of the spiritual dimension of workers has been neglected for many years. The growing importance of spirituality in the workplace can be seen by launching numerous researches on countless spirituality in management studies and social sciences, as well as the many books that have begun to address this topic. That I started topping as your Such as Spiritual Audit of Corporate America [19]. MSR Group is to address specific spiritual issues within the American Academy of Management in 1999. The authors of $[16,18]$ stressed that there is an urgent need for spiritual engagement among workers due to the ongoing changes in an organizational structure that often leads to a sense of insecurity regarding the individual's place in the organization. Increased insecurity at work arises as a result of the weak relationship between the employee and the employer, when trust between employers and organizations is violated by the low number of employees due to negative economic cycles. This has a double effect. First, it undermines mutual trust, loyalty, and employees' expectations that interests will have their interests and care. Second, restructuring leaves the remaining employees in a fatigue syndrome. The situation of downsizing and restructuring does not encourage employees to invest in relationships with their co-workers, since bonding with colleagues may be short-lived. As a result, the situation is frustrating workers, constant fear, stress, insecurity, and time-related ideas. The result of this culture has a negative impact on the spiritual well-being of workers, as well as a weak healthy lifestyle [7].

Work pressures can pose a threat to workers exposed to various psychological problems. The EU Labor Force Survey (2016) indicates that more than $25 \%$ of employees said their health level was affected by exposure to psychological risks. A Gallup's report in South Asia also confirmed that nearly 62\% of employees are 
"struggling", $24 \%$ "suffering" and only $14 \%$ of respondents categorize them as "thriving." These examples are indications of increased threats. Psychological stress such as fatigue, work-life imbalance, stress, etc. (Pandey, 2017: 4) encouraging spirituality in the workplace can lead to benefits in the areas of creativity, honesty, personal fulfillment and commitment, which will ultimately result. Research indicates organizations that know that their employees are spiritually 1 . Less fearful and more confident in their organizations; 2 . Less likely to compromise their core beliefs and values in the workplace; 3 . Imagine their organizations as more profitable; and 4. Highly valued sense of self-management enabling them to be intelligent and creative at work [18].

\section{Workplace spirituality in the 21 st century}

The beginning of the twentieth century aroused increased interest in spirituality within organizations around the world, we often find social, economic and environmental problems [16]. In our daily lives, organizations play more dangerous roles and much more important than we imagined previously .One of us has become, in all his movements, walking in organizational frameworks. It remains in direct and indirect contact with an infinite number of organizations to meet the needs of everyday life. However, the serious effects of organizations in our lives cannot be seen only as positive and useful organizations often seize important aspects of our lives and place them at the disposal of officials, experts, managers and supervisors who are not subject to our personal control. Hence, organizations have become models of power and control that dictate many patterns of thought and behavior that we cannot often reject or resist [10]. Similarly, changes in the global economy, such as restructuring, Globalization, diversity, Competition, downsizing, re-engineering, aging of the population, as well as environmental pollution, led to a recognition at the organizational level that current structures and policies were no longer appropriate in the 21 st century. Workers became frustrated, isolated and unable to deal with the divided nature of their work and their non-working lives. Community structures granted to employees previously provided them with a moral source, but are now perceived to be less important [25]. The downsizing, re-engineering, and layoffs of the past decade have transformed the American workplace into an environment in which workers feel morale [3].

This situation is not limited to American organizations, but we find it in most countries of the world, especially as we live in a time of globalization, which turned the world into a small village. Therefore, organizations in the present era face many obstacles due to the absence of spirituality in the workplace, for example: stress, absenteeism and organizational policy [13]. Since the advent of technology and computers that allow remote communication, this has sometimes led to isolation and a sense of isolation with other workers who work and communicate only through computers [18].

According to an in-depth study of 169 individuals in 73 households in Pittsburg. These families were studied within the first two years of their use of the Internet. The goal of most of the use of the Internet is to achieve communication with others. A number of psychological tests were conducted for those who participated in the study before and after the study. Comparisons have shown interesting results, the most important of which is that the more people use the Internet, the more:

- Less contact with other members of the family

- I said circle of acquaintances and friends

- Increased loneliness

- They showed signs of frustration and depression

These results indicate that the use of the Internet and computers negative psychological effects did not occur to one of us and we may talk about straining our eyes and our backs and wrists as a result of the long time we spend in front of computers. It is therefore the duty of modern organizations interested in maintaining a 
healthy working environment for their workers and to be aware of and address these challenges, which leads to the cost of workers to stay a long time in front of computers [11]. These challenges have resulted in a clear reduction in stability and job security has increased the uncertainty and contributed to the decline of work ethics and high anxiety and the emergence of cases of fatigue and job fatigue in contemporary organizations, and without a doubt, workers who are constantly confronted with the fear of losing their jobs or suffering from the state of stress, they are likely to search for resources Which provides them or give them value and significance of the work is clear [2]. Therefore, the spirit of the workplace has gained a great deal of attention during the last ten years within the literature of organizational behavior, human resources, ethics and social responsibility of the organizations and related topics and a wide and focused attention by organizations and researchers [23]. Then, and to cope with these developments and to handle these challenges, it is the duty of senior management in organizations to recognize that spirituality in the workplace is a learnable behavior, so HRM should try to include it in its training programs [3]. In developing the knowledge and skills of workers, requiring an inspiring workplace environment and efficiency as well as confirmation and affiliation, assisting workers in expressing and achieving the full anticipated demand for the development of people's knowledge and skill is often beyond the requirements of the job, and worker development should include knowledge, values and trends beneficial to the whole organization. Empowerment is also an important path for staff development and growth. It is a multidimensional concept that includes: the meaning of work, autonomy, selfefficacy, and the impact of organizational results [22].

\section{The results of the internal consistency test}

The results of the stability test or the internal consistency came through the correlation coefficient (Cronbach Alpha) as it is used to measure the stability of the measuring instrument in terms of the internal consistency of the instrument terms as it can be illustrated in Table 1, with which the internal consistency of the measure paragraphs at the level of all dimensions was confirmed. After the values of the correlation coefficients (Cronbach Alpha) exceeded the acceptable minimum of (0.70), confirming the internal consistency of the scale and thus the stability of the requirement in the event of repeated testing.

Table 1 . The results of the internal consistency test for the workplace spirituality variable

\begin{tabular}{lrc}
\hline \multicolumn{1}{c}{ Standard } & Honesty & Kronbach Alpha \\
\hline Spiritual Orientation & 0.945 & 0.894 \\
Compassion & 0.946 & 0.895 \\
Meaningful Work & 0.941 & 0.885 \\
Alignment of Values & 0.973 & 0.947 \\
workplace spirituality & 0.979 & 0.959 \\
\hline
\end{tabular}

\section{Stability of the questionnaire}

The split-Halv method is used to measure stability, which is summarized by finding the correlation coefficient between the individual question scores and the marital question scores in the questionnaire. The correlation coefficient is corrected by the Spearman -Brown equation. According to the formula, it is sufficient for the research that the questionnaire adopts as a tool for it, and when applying this method it was found that the correlation coefficient of the questionnaire reached (0.946), which means that with its various measures it has good stability and can be adopted at different times and for the individuals themselves and give the same results.

\section{Confirmatory factor analysis}

The purpose of constructive assertiveness is to verify the dimensions and paragraphs that constitute them according to their fixed theoretical structure in the literature, meaning making sure that the dimensions of the scale and the paragraphs represented in the sample data match with their origin in the theory and related 
literature, and this type of factor analysis is one of the modeling applications The structural equation implemented through the statistical program (AMOS v.23), through which the stability of the scale can be tested, as the quality of conformity indicators [18], given in Table 2 will be used to find out the suitability of the paragraphs in general And the variable that belongs to him in $\mathrm{x}$ image 'S share. Table 2 shows the indicators of conformity quality.

Table 2 . The indicators of conformity quality

\begin{tabular}{lc}
\hline \multicolumn{1}{c}{ Indicator } & General base \\
\hline $\mathrm{X}^{2}$ & --- \\
(DF) Degree of freedom & --- \\
The ratio between X2 and the degree of freedom DF & Less than 5 \\
Comparative Matching Index (CMI) & $1-0.9$ \\
(LFI) Lewis Frequency Index & $1-0.9$ \\
(RMSEA ) & $0.10-0.08$ \\
\hline
\end{tabular}

\section{Empirical factor analysis of the workplace spirituality}

Figure 2 shows the empirical factor analysis of the spirituality of the workplace, which consists of four basic dimensions consisting of (30) paragraphs, and by observing the indicators of the quality of the extract taken out for the model and the phenomenon in the Figure 2 it appears that most of these indicators are not identical and to improve these indicators we will amend them According to the recommendations of the Modification Indices [4], since the indicators of modification indices are intended for the researchers to develop their model based on the literature or research theory, then try to test the extent to which his model matches the experimental data. The common procedure is modification model by deleting paragraphs or tracks of the function and the addition of paragraphs that improve the matching model, and after making the necessary adjustments to be the final adjustment after the specimen as shown in Figure 3.

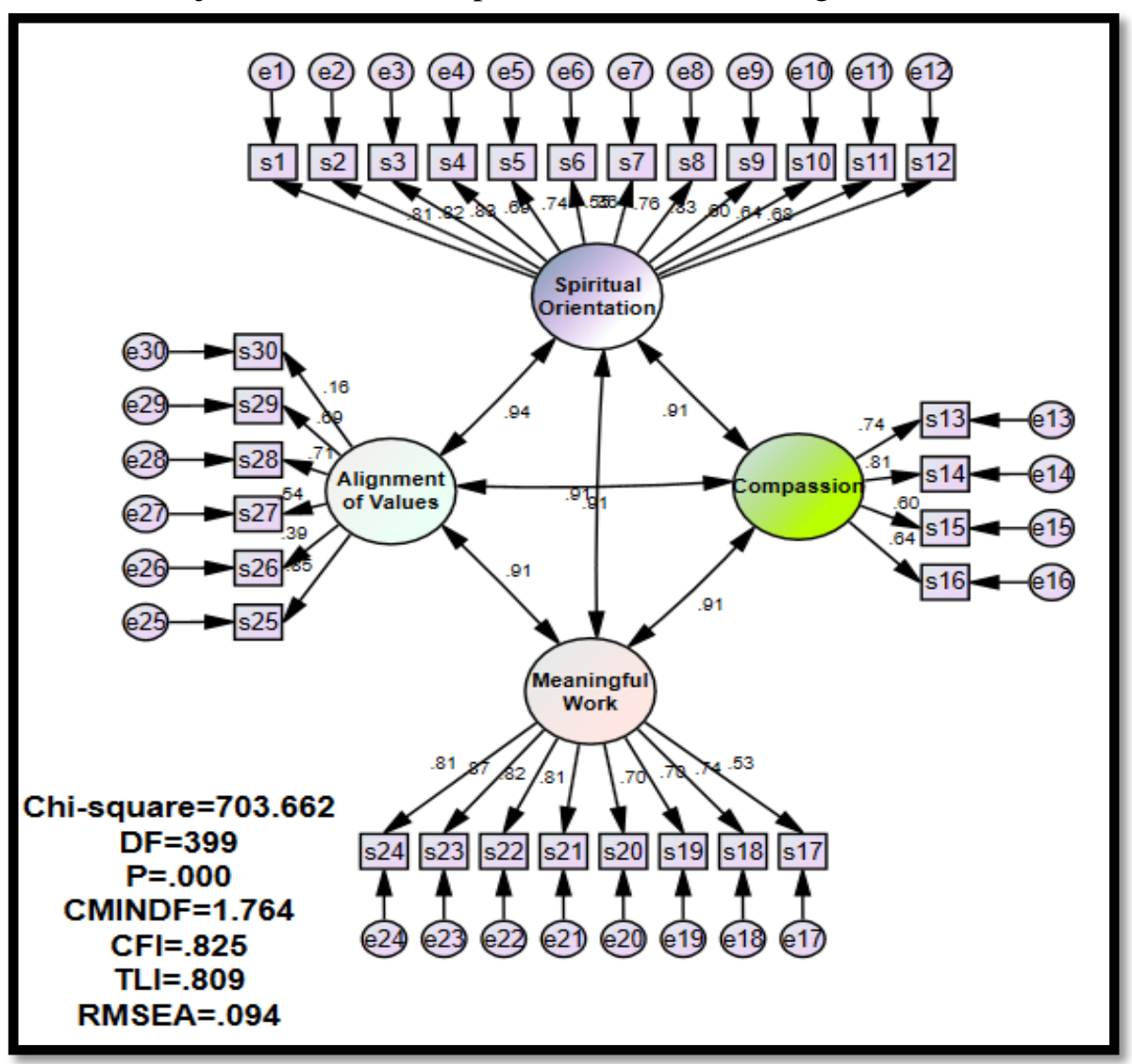

Figure 2. The empirical factor analysis of the spirituality of the workplace 


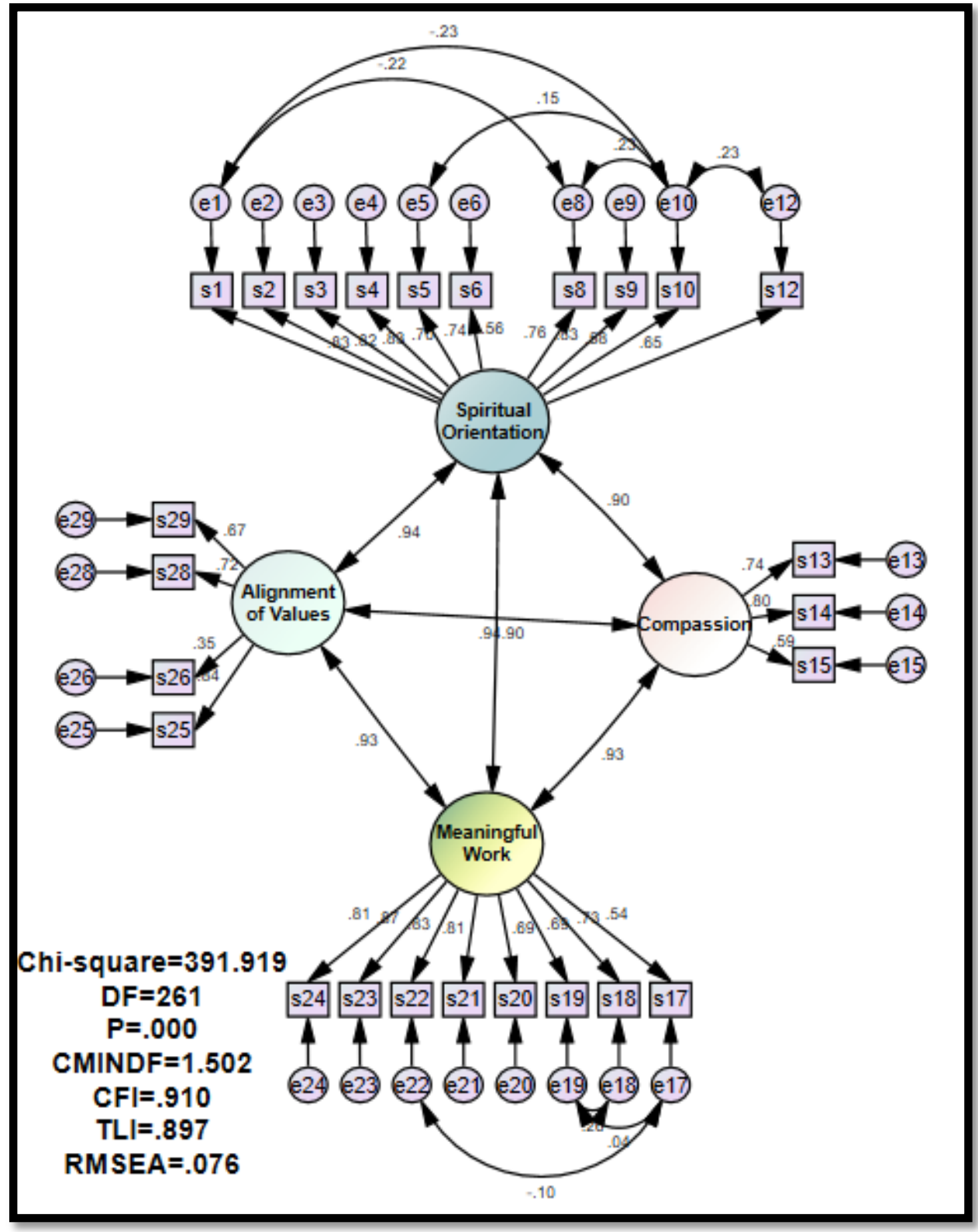

Figure 3. Modification model by deleting paragraphs of the function and the addition of paragraphs that improve the matching model

As it becomes clear through Figure 3 that conformity quality indicators were within the required criteria for the model and it is clear through Table 3 the morale of the paragraphs, as it was found that all paragraphs are greater than the critical standard value (CR) of (1.96) and this indicates the validity of the phrases and that quality indicators The extracted match is close to the Goodness Of Fit quality indicators and is a good indicator. It should be noted here that paragraph $(11,11,16,27)$ was deleted because it was insignificant in addition to adjusting the values of common differences by making a link between the paragraphs with the highest common variance that appeared in the recommendations of the Modification Indices [4]. As these recommendations include either deleting the paragraphs with the highest common, high variance within the model or amending them the amendment has been made and as shown in Figure 3 of the workplace spirituality variable after the amendment.

Table 3 shows the regression weights, standard error, critical ratio, in addition to the significance level for the spirituality dimensions variable in the workplace. 
Table 3. The regression weights, the standard error, the critical ratio, and the significance level for the dimensions of the spirituality variable in the workplace

\begin{tabular}{|c|c|c|c|c|c|c|}
\hline Paragraphs & Path & Dimensions & $\begin{array}{l}\text { Standard } \\
\text { regression } \\
\text { weights }\end{array}$ & $\begin{array}{l}\text { Standard } \\
\text { error } \\
\text { S.E. }\end{array}$ & $\begin{array}{l}\text { The } \\
\text { critical } \\
\text { ratio } \\
\text { C.R. }\end{array}$ & $\begin{array}{l}\text { Significance } \\
\text { level at } \\
\text { 0.05 } \\
\text { P }\end{array}$ \\
\hline s1 & <--- & \multirow{10}{*}{$\begin{array}{c}\text { Spiritual } \\
\text { Orientation }\end{array}$} & .828 & & & \\
\hline $\mathrm{s} 2$ & $<--$ & & .820 & .110 & 9.246 & $* * *$ \\
\hline s3 & <--- & & .834 & .108 & 9.494 & $* * *$ \\
\hline s4 & $<--$ & & .703 & .111 & 7.422 & $* * *$ \\
\hline s5 & <--- & & .744 & .096 & 8.014 & $* * *$ \\
\hline s6 & <--- & & .559 & .111 & 5.561 & $* * *$ \\
\hline s8 & $<--$ & & .760 & .095 & 7.508 & $* * *$ \\
\hline s9 & $<--$ & & .829 & .092 & 9.402 & $* * *$ \\
\hline s10 & <--- & & .576 & .097 & 5.276 & $* * *$ \\
\hline s12 & <--- & & .653 & .095 & 6.736 & $* * *$ \\
\hline s13 & <--- & \multirow{3}{*}{ Compassion } & .735 & & & \\
\hline s14 & <--- & & .799 & .124 & 7.337 & $* * *$ \\
\hline s15 & $<---$ & & .587 & .119 & 5.315 & $* * *$ \\
\hline s17 & $<---$ & \multirow{8}{*}{$\begin{array}{l}\text { Meaningful } \\
\text { Work }\end{array}$} & .536 & & & \\
\hline $\mathrm{s} 18$ & $<--$ & & .730 & .298 & 4.912 & $* * *$ \\
\hline s19 & $<--$ & & .686 & .329 & 4.825 & $* * *$ \\
\hline $\mathrm{s} 20$ & $<--$ & & .694 & .322 & 4.776 & $* * *$ \\
\hline s21 & <--- & & .813 & .317 & 5.200 & $* * *$ \\
\hline $\mathrm{s} 22$ & <--- & & .826 & .362 & 5.068 & $* * *$ \\
\hline $\mathrm{s} 23$ & <--- & & .872 & .378 & 5.375 & $* * *$ \\
\hline s24 & $<--$ & & .810 & .350 & 5.190 & $* * *$ \\
\hline $\mathrm{s} 25$ & $<--$ & \multirow{4}{*}{$\begin{array}{r}\text { Alignment of } \\
\text { Values }\end{array}$} & .843 & & & \\
\hline s26 & $<---$ & & .349 & .108 & 3.254 & .001 \\
\hline $\mathrm{s} 28$ & $<---$ & & .717 & .091 & 7.653 & $* * *$ \\
\hline s29 & <--- & & .675 & .102 & 7.035 & $* * *$ \\
\hline
\end{tabular}

\section{Descriptive analysis of the search variable}

We seek from this analysis to identify the reality of workplace spirituality for the research sample in the Iraqi Ministry of Health, and the mean and standard deviation of these answers will be relied on in addition to determining the level of relative importance of each dimension within the single variable depending on the coefficient of difference. The research relied on the quintuple Likert scale in the sample's answers to the questionnaire, so the level of each variable will be between (1-5) with four levels and the Table 4 illustrates this, and includes two levels in the case of an increase from the hypothetical mean of (2.60 to 3.39) It is good if it ranges between (3.40 to 4.19) and very good if it increases from (4.20 to 5) It also includes two levels if it falls below the hypothetical mean (2.60 to 3.39) and it is weak if it ranges between (1.80 to 2.59) and very weak if it decreased from 1 to 1.79 . 
Table 4. The weighted average and the direction of the answer

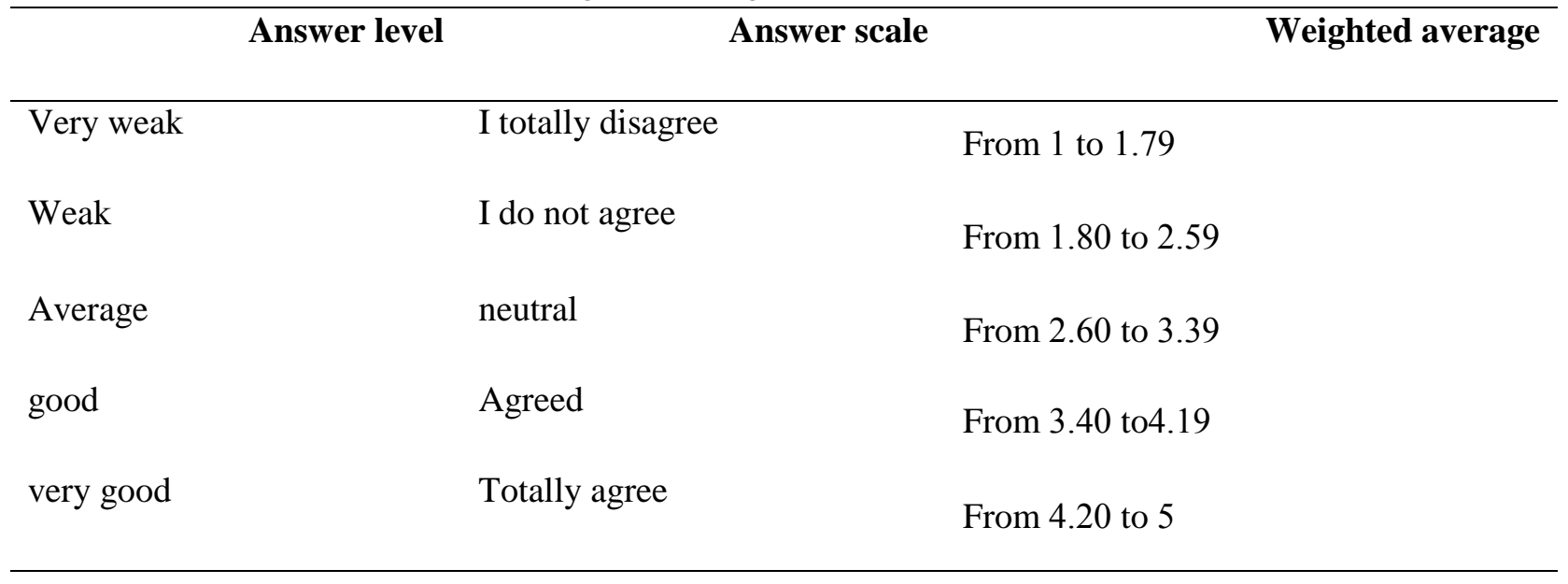

\section{Workplace spirituality $(\mathbf{X})$}

The highest general arithmetic mean in the spirituality variable of the workplace is reached after the spiritual orientation, as the arithmetic mean has a value of (3.257) which is higher than the hypothetical medium and at an average level as the standard deviation of it (0.618) and a coefficient of difference (18.97) came as this dimension came in the second level in terms of Relative importance, and this indicates the existence of spirituality in the workplace, but it is not at an acceptable level, because despite the existence of a source of work spirituality that guides workers, which is religion and the conscience that encourages work and dedication to work, but it is not sufficient as a result of the general climate in the ministry, which Focuses only on the formal routine and neglects the spirit Me, most of the time, workers feel that the workplace is not characterized by happiness or rest during work, besides that contact with the top management does not add energy or positive high guidelines that generally affect Spiritual orientation of employees.

As for the lowest dimension in the spirituality of the workplace, it was to the purposeful work dimension that came with an arithmetic mean (3.124), an average level, a standard deviation (0.707), a different coefficient (22.63), and a significance level (4) and this indicates that there is a decline in meaningful work in the research sample In the Ministry of Health, as most workers do not feel high spirits or enjoyment at work, which has affected levels of satisfaction within the work environment for workers and therefore these factors have negatively affected enthusiasm and impulsivity, which has lost the acceptable level of meaningful work. As for the aggregate, the spirituality of the workplace has achieved a workplace mean (3.201) with an acceptable level and a standard deviation (0.521). This indicates the lack of dispersion of the sample responses and their assertion that spirituality in the workplace of the researched Ministry of Health is present but is not at the level of ambition and actor who It affects workers and creates spirituality within the work environment.

The researchers noted that the main problem that the Ministry of Health suffers from within the work environment is the presence of negligence and lack of interest in the spiritual behavioral aspect of the workers and focus only on the official aspects and how to achieve the goals in isolation from the mechanism or how to reach For those who are guided They are the workers who need spiritual attention and care, and that is what we did not find clearly effective within the Ministry of Health, especially in terms of sympathy that has been weakened among the workers as a result of creating the gap between them as a result of lack of focus on the spiritual side and perhaps the reason for this is that Most of the higher management in the ministry are from the category of doctors who are from medical specialties and not administrative, and this has negatively affected how the correct behavioral and administrative dealing with workers is effective. Table 5 displays the mean, the standard deviation, the coefficient of variation, and the relative importance of the search variables 
Table 5. Mean, the standard deviation, the coefficient of variation, and the relative importance of the search variables

\begin{tabular}{lcccc}
\hline $\begin{array}{l}\text { Dimension the search } \\
\text { variable }\end{array}$ & $\begin{array}{c}\text { Arithmetic } \\
\text { mean }\end{array}$ & $\begin{array}{c}\text { Standard } \\
\text { deviation }\end{array}$ & Coefficient of variation & $\begin{array}{c}\text { Relative } \\
\text { importance }\end{array}$ \\
\hline Spiritual Orientation & 3.257 & 0.618 & 18.97 & 2 \\
Compassion & 3.193 & 0.669 & 20.95 & 3 \\
Meaningful Work & 3.124 & 0.707 & 22.63 & 4 \\
Alignment of Values & 3.229 & 0.446 & 13.81 & 1 \\
\hline workplace spirituality & 3.201 & 0.521 & 16.28 & - \\
\hline
\end{tabular}

\section{Conclusions}

1. The subject of spirituality in the workplace is not considered the birth of the last few years, but the school of human relations through Hawthorne studies is the real starting point and the main seed of the subject of spirituality in the workplace.

2. Despite the developments in the field of electronic and industrial intelligence, it was expected to underline the calculator on everything in the organization, but the reality has proved that it is indispensable to humans and not only this, but cannot neglect the emotional and spiritual side of the workers as these developments technological has negatively affected the process of social communication between employees and increased sense of isolation, which adversely affected the levels of performance and creativity at work, so it was necessary to increase the actual attention to the spiritual reality in the workplace and evidence that some organizations began to establish sections especially deals with the subject of the soul intention in the workplace and as practiced within the American Academy of Management Spirituality and the Religious Interest Group (MSR Group) to handle specific spiritual issues.

3. The large number of economic changes, technology and intense competition have made the workers in constant concern as they at any moment threatened to lose their work and thus this created psychological pressure and nervous stress for workers, which negatively affected their performance levels, so it was necessary for the senior management to realize this problem by activating spirituality in the workplace and emphasizing the positive and spiritual aspect for the individual, the organization and for both parties.

4. Spirituality in the workplace refers to an inspiring and motivating force that encourages the individual to continuously seek meaning and aim in his or her vocational life, to understand the true value of work, and to recognize the diversity of systems of creativity, nature and personal belief.

5. The literature emphasizes the spirituality of the workplace that promotes both initiative and creativity. It helps individuals to expand their knowledge, and self-efficacy where spirituality is specifically linked to Maslow's hierarchy of needs in terms of sense of belonging and increased spirituality promotes emotional loyalty in life and work.

6. The results proved the weak interest of the Ministry of Health in the spirituality of the workplace, as a result of the Ministry's focus on routine official aspects and neglecting the spiritual aspects, feelings and feelings of the workers, which generally affected the organizational climate of the Ministry, which lost it the element of spiritual interaction that is most needed as a result of the Ministry's work that There must be spirituality in the workplace.

7. There is a decline in sympathy levels within the Ministry of Health, and the reason for this is the result of negligence on the behavioral side by the higher management of the Ministry and the lack of active interest in the workers behaviors and their personal lives that sometimes affect their job 
performance and therefore this worked to cause a decline in dealing levels Spiritual among the workers among themselves within the ministry and at the spiritual level in general in the ministry.

8. The results showed that there are organizational values for the Ministry of Health, but they are not effective on the ground, as there is no focus on how to activate those values in order to raise the morale of workers in order to enhance the spirit of work or create motivation for them, and therefore that the continuation of this will lead over time to the feeling of isolation and workers They do not feel that they are part of the ministry or part of its goals.

\section{References}

[1] S.A. Al-Enezi, "Theory of the Organization concepts approaches - processes" Publishing and distribution of the CISPAN Library, 2015.

[2] A. A. M. Al-Shami, " The spirituality of the workplace and its repercussions on the behavior of citizenship by mediating the attractiveness of organizational identity", Thesis submitted to the Board of the -Faculty of Business and Economics at Karbala University, which is part of the requirements for obtaining the Master of Science in Business Administration,2014.

[3] M. J. Aldridge, H. J. Macy, T. Walz, "Beyond management: Humanizing the administrative Process", Iowa City, IA: University of Iowa, School of Social Work, 1982.

[4] C. Argyris, "Integrating the individual and the organization", New York, NY: Wiley, 1964.

[5] D.P. Ashmos, and D. Duchon, "Spirituality at work: A conceptualization and measure". Journal of management inquiry, vol. 9, no.2, pp.134-145,2000

[6] J. Daniel (2010). The effect of workplace spirituality on team effectiveness. Journal of Management Development, vol.29, no.5, pp.442-456, 2010.

[7] M. B. Barbara, "2th Structural Equation Modelling with AMOS Basic Concepts", Applications, and Programming p:90, 2009.

[8] E. Abdel-Fattah, "An introduction to descriptive and inferential statistics using SPSS", edited by Dar AlKhwarizmi for Printing and Publishing, p. 451, 2008.

[9] J. L. Daniel, "A study of the impact of workplace spirituality on employee outcomes: A comparison between US and Mexican employees", Doctoral dissertation, Texas A\&M International University, 2012.

[10] P. Leigh, "The new spirit at work", Training, vol.51, no.3,pp. 26-33, 1997.

[11] M. Fourie, "Spirituality in the workplace: An introductory overview. In die Skriflig", Faculty of Theology, North-West University, Potchefstroom Campus, South Africa. http://www.indieskriflig.org.za, vol. 48, no.1, pp. 01-08, 2014.

[12] P. Khatri1, P. Gupta, "Workplace Spirituality: A Predictor of Employee Wellbeing “ , A\&V Publications all right reserved Asian J. Management; 8(2): 284-292, 2017.

[13] R.A. Giacalone and C.L. Jurkiewicz, (Eds.), "Handbook of workplace spirituality and organizational performance". pp. 3-28. Armonk, NY: Me Sharpe, 2003.

[14] R. Giacalone and C. L. Jurkiewicz, "Toward a science of workplace spirituality", in R. A.: https://www.researchgate.net/publication/280686151, 2003.

[15] G. Anthony, F. Sabbagh, "Translation, Arab Organization for Translation, Distribution of the Center for Arab Unity Studies", Lebanon, Beirut, 4th Edition, 2005.

[16] G. Greenberg and R. Barron, "Management of Behavior in Organizations", Translated by Rifai Mohammed Rifai and Ismail Ali Bassiouni, Mars Publishing House, Riyadh, Saudi Arabia, 2009.

[17] M. Gouda, "basic statistical analysis using SPSS", Wael Publishing House, second edition, pp. 295305,2009 .

[18] J.F. Hair, W.C. Black, B.J. Babin, R.E. Anderson, " Multivariate Data Analysis " ,7th ed., Prentice Hall, Upper Saddle, 2010.

[19] G. Henderson, "Human relations issues in management", Westport, CT: Quorum Books, 1996. 
[20] G. N. P. Konz, F. X. Ryan, "Maintaining an organizational spirituality: No easy task", Journal of Organizational Change Management, vol.12, no.3, pp.200-210, 1999.

[21] M. Hassan, A. Bin-Nadeem and A. Akhter, "Impact of workplace spirituality on job satisfaction: Mediating effect of trust", Cogent Business \& Management, vol.3, no.1, 1189808, 2016.

[22] J.F. Hair, W.C. Black, B.J. Babin and R.E. Anderson. "Multivariate Data Analysis" ,7th ed., Prentice Hall, Upper Saddle. , Chan, F., Lee, G., 2010.

[23] E. Lee, C. Kubota and Ch. Allen, "Structural Equation Modeling in Rehabilitation Counseling Research", Rehabilitation Counseling Bulletin, vol.51, no.1, pp.53-66, 2007.

[24] P. Khatri and P. Gupta, "Workplace Spirituality: A Predictor of Employee Wellbeing", Asian Journal of Management, vol. 8, no.2, pp. 284-292, 2017.

[25] R.W. Kolodinsky, R.A. Giacalone and C.L. Jurkiewicz, Workplace values and outcomes: Exploring personal, organizational, and interactive workplace spirituality. Journal of business ethics, vol.81, no.2, pp. 465-480, 2008.

[26] E. Marschke, R. Preziosi, and W. Harrington, Professionals and executives support a relationship between organizational commitment and spirituality in the workplace. Journal of Business \& Economics Research, vol.7, no.8, pp. 33-48, 2009.

[27] I.I Mitroff and E.A. Denton, A study of spirituality in the workplace. MIT Sloan Management Review, vol.40, no.4, p. 83, 1999.

[28] J. S. Kolb, D. A. Robin, E. M. and Marilyn E. Turner, "Organizational Behaviour as an Experimental Approach", Library of Lebanon Publishers, Beirut, Lebanon, 1th Edition, 2014.

[29] A. Pandey, "Workplace Spirituality: Themes, Impact and Research Directions", South Asian Journal of Human Resources Management, vol. 4, no.2, pp.212-217, 2017.

[30] S. H. Raheema, "The Effect of Organization Spirituality on the Quality of Health Services through Positive Attitudes of Employees Comparative Research of the Opinions of a Sample of Doctors and Nurses in Sadr City Hospitals in Baghdad ", PhD Thesis, University of Baghdad, 2016.

[31] R. N. Sabr, "The mediating role of workplace spirituality in the relationship between psychological capital and entrepreneurial behavior: a field research in the center of the Iraqi Ministry of Oil", Journal of Economic and Administrative Sciences, vol.24, no. 103, 2018.

[32] K. M. H. Al-Shama, "Principles of management with a focus on business management", Dar Al-Masirah for publication, distribution and printing, 2007.

[33] F. Van der Walt, Workplace spirituality, work engagement and thriving at work. SA Journal of Industrial Psychology, vol.44. no.1, pp.1-10, 2018.

[34] F. Van der Walt and J.J. De Klerk, Workplace spirituality and job satisfaction. International Review of Psychiatry, vol.26, no.3, pp. 379-389, 2014. 